for a 52 year old plumber with extensive malignant pleural mesothelioma, who had been admitted with impaired consciousness and left sided long tract signs and whose computed tomogram showed at least four cerebral metastases, two in the brainstem and two in the right partietal region. Both of these tumours were subsequently confirmed at necropsy. In addition, there was extensive tumour affecting the pericardium, epicardium, and myocardium and extending extensively through the peritoneum.

RA LEWIS

Worcester WR1 $3 A S$

I agree with Dr Lewis that the small number of published cases of antemortem diagnosis of cerebral metastases in pleural mesothelioma may be due to underreporting. Unfortunately, I do not have data to support or refute this contention. I reviewed about 200 cases of pleural mesothelioma in 1986-87 and was surprised to find that many physicians were unaware that the tumour often metastasised.

Over the last few years I have developed a strong interest in research examining how scientific data are used in the courts and in public policy decision making. ${ }^{1}$ Through my work in the asbestos area I became aware that injured workers seeking compensation through the courts often faced defence attorneys who vigorously questioned a diagnosis of pleural mesothelioma if metastatic disease was present. This prompted me to review a large number of cases coming to necropsy, and document the occurrence of metastatic spread, which was quite common. ${ }^{2}$ This report also cited earlier studies further supporting this fact.

With the incidence of pleural mesothelioma increasing, cerebral metastases will undoubtedly be found more often. I hope that information such as that detailed by Dr Lewis will find its way into medical publications. In this way confusion concerning the natural history of this disease will be avoided.

MICHAEL HUNCHAREK Boston University School of Medicine Boston, Mass 02118, USA

1 Muscat J, Huncharek M. Causation and disease: biomedical science in toxic tort litigation. $J$ Occup Med 1989;31:997-1002.

2 Huncharek M, Muscat J. Metastases in diffuse pleural mesothelioma: influence of histological type. Thorax 1987;42:897-8.

\section{Local anaesthesia for fibreoptic bronchoscopy}

We read with interest the report by $\operatorname{Dr} A \mathrm{R}$ Webb and colleagues (June 1990;45:474-7) in which they compared transcricoid injection of lignocaine with the traditional "spray as you go" technique. They found the transcricoid technique to be more effective.

On reading the "Methods" section of the paper, one finds that both groups of patients received topical anaesthesia with lignocaine, but that the location and timing of administration differed. Patients who received transcricoid anaesthesia had lignocaine delivered to the subglottic space in an anteroom several minutes before the passage of the bronchoscope, whereas the other group of patients received a topical application of lignocaine to the upper surface of the vocal cords about $1 \frac{1}{2}$ minutes before the bronchoscope was passed between the cords. There were further applications to the bronchi during the procedure.
In these circumstances it is not surprising that the group given transcricoid anaesthesia should cough less. It is likely that the lignocaine which was introduced into the trachea would spread widely in the bronchial tree during the coughing bout which followed the injection. It is also likely that the lignocaine would anaesthetise the inferior and medial surfaces of the vocal cords as it was removed from the bronchial tree by coughing and ciliary action. The bronchoscope is in contact with these surfaces of the vocal cords during bronchoscopy, but the "spray as your go" method would have anaesthetised only the upper surface of the cords. In the absence of any subglottic anaesthesia, one would expect the patient to cough and experience discomfort as the bronchoscope was passed into the unanaesthetised trachea and bronchial tree.

We have evolved a non-invasive technique for the instillation of local anaesthesia into the subglottic space and trachea. It is our practice to anaesthetise the nose and the upper surface of the vocal cords by the techniques described by $\mathrm{Dr}$ Webb and colleagues. We then position the bronchoscope directly above the vocal cords and we introduce $2-4 \mathrm{ml}$ of $4 \%$ lignocaine as a bolus during inspiration. This enters the trachea and main bronchi and produces a cough similar to that occurring after transcricoid injection of lignocaine. We then wait two to three minutes before proceeding with the bronchoscopy and we find the operating conditions to be as good as those described after transcricoid lignocaine.

Our technique avoids a transcricoid injection but it has two potential disadvantages. Firstly, it may add one to two minutes to the duration of the bronchoscopy; we find this to be an acceptable delay. Secondly, our technique requires an experienced bronchoscopist to guarantee subglottic placement of the lignocaine. In difficult cases where both hands are required to optimise the position of the bronchoscope, we get an assistant to introduce the subglottic bolus of lignocaine while we observe the vocal cords through a lecturescope or on a video monitor.

We would therefore agree that transcricoid injection of lignocaine may have certain advantages, especially as it will achieve good anaesthesia of the glottis and trachea for trainee bronchoscopists. We suggest that experienced bronchoscopists might prefer to administer anaesthesia by the above noninvasive technique at the cost of a slight increase in operating time.

B RONAN O'DRISCOLL PHILIP V BARBER Department of Thoracic Medicine, Wythenshawe Hospital, Manchester M23 9LT

We read with interest the article by $\operatorname{Dr} A \mathrm{R}$ Webb and others (June 1990;45:474-7). Transtracheal injection of topical anaesthetic has been widely used for bronchoscopy, bronchography, and endotracheal intubation since this method was first suggested by Caynut' in 1920. Hitherto, a few complications, such as cellulitis, breakage of the needle, and pretracheal abscess, have been reported. ${ }^{2-4}$

Previous reports recommended inserting the needle perpendicularly to the skin through the cricothyroid membrane. This may cause laceration of the trachea as a result of coughing while the local anaesthetic is injected, and we witnessed a case of bleeding due to tracheal laceration many years ago. We therefore devised this technique to prevent this potential complication. A 23 gauge

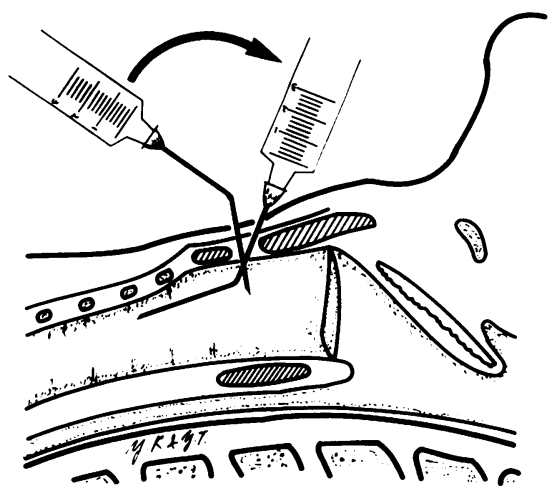

Diagram illustrating the technique of transtracheal injection with a bent needle.

hypodermic needle is bent aseptically about $45^{\circ}$ at a point $1 \mathrm{~cm}$ from the tip with a cap of the needle. A bent needle, attached to a $5 \mathrm{ml}$ syringe containing $3 \mathrm{ml}$ of anaesthetic, is inserted perpendicularly into the trachea through the cricothyroid membrane. Easy aspiration of air confirms that the needle is within the tracheal lumen. Then the syringe is directed cephalad at an angle of about $90^{\circ}$ while air is aspirated and the needle is advanced about $0.5 \mathrm{~cm}$. This procedure makes the bent part of the needle parallel to the anterior wall of the trachea (figure). Thus there is no possibility of traumatising the trachea or dislocating the needle while the anaesthetic is instilled even if the patient coughs persistently.

We have used this technique for more than 20 years before endotracheal intubation and also for instillation of saline or mucolytic agents for treating and preventing postoperative pulmonary complications together with diazepam ${ }^{5}$ and midazolam. No troublesome complications have been noted after more than several thousand injections, confirming the safety of this technique.

YUKIO KUBOTA YOSHIRO TOYODA HIROSHI KUBOTA Department of Anaesthesia, Osaka Kohseinenkin Hospital, Fukushima-Ku, Osaka, Japan 553

1 Caynut G. Anesthesia locale en Otorhinolaryngologie. Science Medicale de Bordeaux 1920;41:266-9.

2 Harken DE, Salzberg AM. Transtracheal anesthesia for bronchoscopy. $N$ Engl J Med 1948; 239:383-5.

3 Bonica JJ. Transtracheal anesthesia for endotracheal intubation. Anesthesiology 1949;10 736-8.

4 Adriani J, Parmley J. Complications following transtracheal anesthesia. Am J Surg 1952; 84:11-2.

5 Kubota Y, Uchida I, Kimachi H, et al. The amnesic effects of diazepam for intubation. Excerpta Medica International Congress Series 1972;16:473.

\section{CORRECTION}

The hyperimmunoglobulinaemia $\mathbf{E}$ and recurrent infections syndrome in an adult

In the paper by J-P L'Huillier et al (September 1990;45:707-8), the 4th line from the end of $p 707$ should read " $(0.54 \times$ $\left.10^{9} / 1\right) \ldots$. 